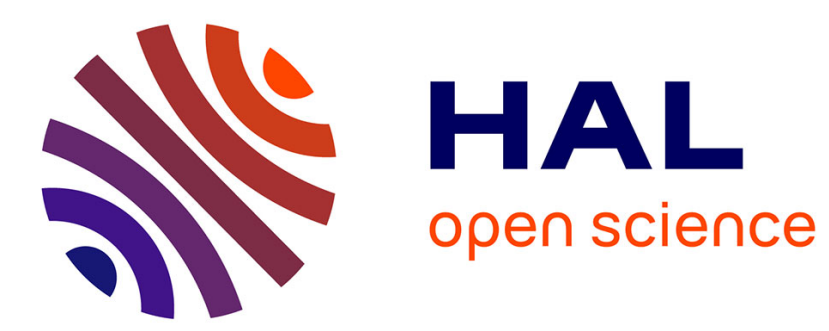

\title{
EL2 family in LEC and HB GaAs
}

Y. Mochizuki, T. Ikoma

\section{- To cite this version:}

Y. Mochizuki, T. Ikoma. EL2 family in LEC and HB GaAs. Revue de Physique Appliquée, 1988, 23

(5), pp.747-763. 10.1051/rphysap:01988002305074700 . jpa-00245880

\section{HAL Id: jpa-00245880 https://hal.science/jpa-00245880}

Submitted on 1 Jan 1988

HAL is a multi-disciplinary open access archive for the deposit and dissemination of scientific research documents, whether they are published or not. The documents may come from teaching and research institutions in France or abroad, or from public or private research centers.
L'archive ouverte pluridisciplinaire HAL, est destinée au dépôt et à la diffusion de documents scientifiques de niveau recherche, publiés ou non, émanant des établissements d'enseignement et de recherche français ou étrangers, des laboratoires publics ou privés. 
Classification

Physics Abstracts

71.55E $-78.20 \mathrm{~J}$

\title{
EL2 family in LEC and HB GaAs
}

\author{
Y. Mochizuki and T. Ikoma \\ Institute of Industrial Science, University of Tokyo 7-22-1, Roppongi, Minato-ku, Tokyo 106, Japan
}

(Reçu le 15 juillet 1987, accepté le 8 janvier 1988)

\begin{abstract}
Résumé. - On décrit des études sur les propriétés électriques et optiques de EL2 dans différents cristaux de GaAs en vue de cerner les caractéristiques de cette famille de défauts. On donne tout d'abord une revue de la variation des niveaux d'énergie associés à la «famille» EL2. On montre que les caractéristiques de cette famille sont observées aussi bien dans les effets de photoblocage (transition entre l'état normal et l'état métastable) que dans les taux de transition vers les états excités. La modification des centres EL2 après irradiation aux particules lourdes et recuits à basse température indique que la structure du défaut associé à EL2 est assez étendue et qu'elle inclut un ou des interstitiels d'arsenic. A partir des résultats expérimentaux, la validité du modèle d'ensemble d'atomes d'arsenic pour EL2 est corrélée à des modèles présentés par d'autres auteurs.

Abstract. - Studies on the electrical and optical properties of EL2 in various GaAs crystals are described especially in view of the family characteristics. A variation in the trap energy levels among the EL2 family is first reviewed. It is shown that the family characteristics are also observed in the photoquenching effect (transitions between the normal and the metastable states) as well as the transition rate to the excited state. Change of EL2 centers after heavy particle bombardment and low temperature annealing indicate that the defect structure responsible for EL2 is sizable, in which mobile interstitial As atom(s) are involved. Based on the experimental results, validity of the As-cluster model for the origin of EL2 is presented and correlated with the models proposed by other investigators.
\end{abstract}

\section{Introduction.}

EL2 is the native midgap electron trap in GaAs which plays a dominant role in achieving semiinsulating (SI) property of GaAs without intentional doping. Due to its importance from both basic and practical viewpoints, intensive studies have been carried out in order to clarify the microscopic defect structure. In spite of such efforts, the origin of EL2 is still controversial.

Sakai and Ikoma [1] first reported the thermal emission property of this midgap level. After that, people have reached an agreement on the energy level and the capture cross section as summarized in reference [2]. Studies on the energy barrier for electron capture process [3] and the large FranckCondon shift [4] have revealed that EL2 undergoes a lattice relaxation on capturing electron. Moreover, peculiar characteristics of EL2 are also reported; a large metastable relaxation (so called photoquenching effect [5]) and the existence of an internal excited state [6]. These findings are very important for discussing the atomic structure of EL2.

Since Huber et al. [7] excluded the possibility that EL2 is oxygen impurity-related, roles of native point defects have been studied as a candidate for the origin of this level. The early electron spin resonance (ESR) studies [8] combined with the growth condition dependence [9] lead to an idea that an As atom at the $\mathrm{Ga}$ site (the arsenic antisite, $\mathrm{As}_{\mathrm{Ga}}$ ) is responsible for EL2, which is in agreement with the prediction by Van Vechten [10] in 1975. However, some difficulties in attributing an isolated $\mathrm{As}_{\mathrm{Ga}}$ to EL2 have been pointed out both experimentally [11] and theoretically [12]. An isolated antisite has little lattice relaxation and should have no metastability [12]. These features are different from experimental observations. As a consequence, various $\mathrm{As}_{\mathrm{Ga}}$-related complex defect models have been considered.

In 1983 , it was further reported by the present authors' group that EL2 is not a well defined single level but a group of midgap levels with similar 
properties $[13,14]$. They first pointed out that all of the variation in thermal emission rate reported by several researchers cannot necessarily be attributed to an experimental error but it should be an actual variation in the trap properties. Because of a common characteristic of the photoquenching effect, they concluded that these traps belong to the same "family". This conclusion has also provided an alternative approach to an identification of EL2 ; the excess As-cluster model proposed in 1984 [14].

In this paper, we focus our attention on the family characteristics of EL2. The main portion is devoted to the description of our recent results on the optical properties of EL2 together with a review of our earlier results. Section 2 deals with the variation in thermal and optical characteristics among the family in various GaAs crystals. When the defect structure is to be argued, it is also useful to study its stability. The experimental results on this point are described in section 3. Finally in section 4, validity of our Ascluster model for the origin of EL2 is shown and comparative discussions with other models are made. Section 5 is the summary of the present study.

\section{Variation in properties of EL2 family.}

\subsection{CARRIER EMISSION PROPERTIES.}

a) DLTS measurement. - A variation in the thermal emission rate among the EL2 family in LEC GaAs crystals was first reported by Taniguchi and Ikoma [12], who measured capacitance DLTS spectra in various LEC GaAs crystals. In order to assure large Schottky-barrier height, all the measurements were carried out by using Au-evaporated Schottky diodes which have usually $0.85-0.90 \mathrm{eV}$ barrier height. We found that the peak temperatures of DLTS spectra for EL2 show a variation depending on measured spots, wafers or annealing.

The DLTS spectra measured in two LEC-grown samples are shown in figure 1 . One of the samples is cut from the front (or seed end) section of an ingot, while the other is from the tail section of the same ingot. It is clearly shown that the peak temperature for the midgap level in the front section (ETX-2) is lower than that in the tail section (ETX-1) by more than 20 degrees. Similar variations were also observed by changing bias in measurements and by annealing at $650{ }^{\circ} \mathrm{C}$ for $40 \mathrm{~min}$ [13]. These differences cannot be attributed to an experimental error but should be due to an existence of similar midgap traps (EL2 family).

Figure 2 shows a set of DLTS spectra taken from another ingot. The spectra provides evidence that two midgap levels simultaneously exist in the same region in this LEC GaAs. The spectral shapes in this figure are apparently broader than that expected from a single deep level. Actually, they are well

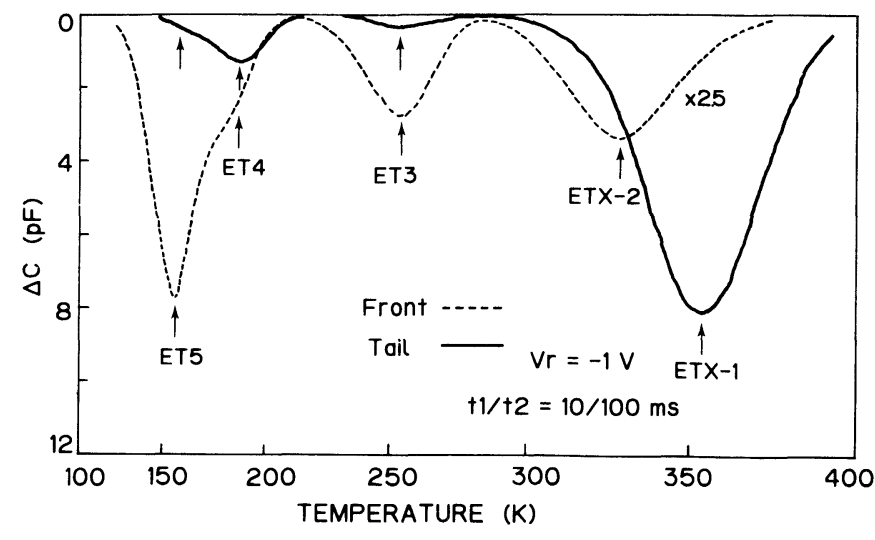

Fig. 1. - DLTS spectra in front and tail sections of an asgrown LEC GaAs crystal. The samples are labeled as LEC-1(F) and LEC-1(T), respectively.

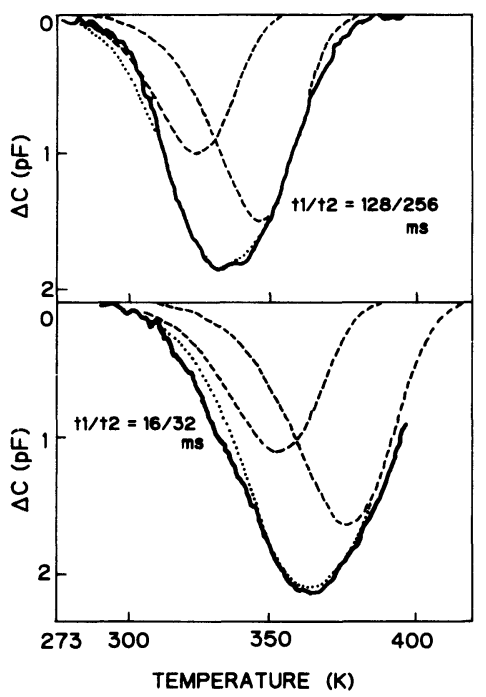

Fig. 2. - DLTS spectra for the midgap level in another LEC GaAs. The calculated curves assuming the existence of two levels are shown.

described by assuming contributions of two midgap levels. In the theoretical fit, activation energy and capture cross section for one of the levels are $0.76 \mathrm{eV}$ and $3.7 \times 10^{-13} \mathrm{~cm}^{2}$ and for the other level $0.81 \mathrm{eV}$ and $4.3 \times 10^{-13} \mathrm{~cm}^{2}$, respectively. The sum (dotted curve) of the calculated curves (broken lines) are in agreement with the experimental curve (solid curve) by assuming the same ratio of concentrations for different rate windows. These trap parameters are almost the same as those of ETX-2 and ETX-3 in reference [13]. The existence of more than two midgap levels were also reported by other research groups $[15,16]$.

b) Steady state photocapacitance measurements. - A variation is also observed in the opticallymeasured energy levels of the EL2 family. Although 
the energy levels of the EL2 family fall within the midgap region, it has been found that there exist two types of levels which have different threshold energies for photoionization. Figure 3 shows the result of quasi steady state photocapacitance spectra at $77 \mathrm{~K}$. The results are for (a) as-grown $\mathrm{HB}$ GaAs, (b) oxygen-implanted and $700^{\circ} \mathrm{C} / 15 \mathrm{~min}$ annealed $\mathrm{HB}$ GaAs and (c) oxygen-implanted and $800^{\circ} \mathrm{C} / 2 \mathrm{~min}$ annealed LPE GaAs. All the samples contain EL2 as a major electron trap. It should be noted that EL2 does not exist originally in LPE crystals. EL2 in HB $\mathrm{GaAs}$ is also annihilated after oxygen ion implantation. However, post-implantation annealing in the range $650-800{ }^{\circ} \mathrm{C}$ creates a new midgap level. This level has a similar energy level to EL2 and shows photoquenching effect as well. Therefore, the newly created level is regarded to belong to EL2 family, which is labeled as EL2-O [17].

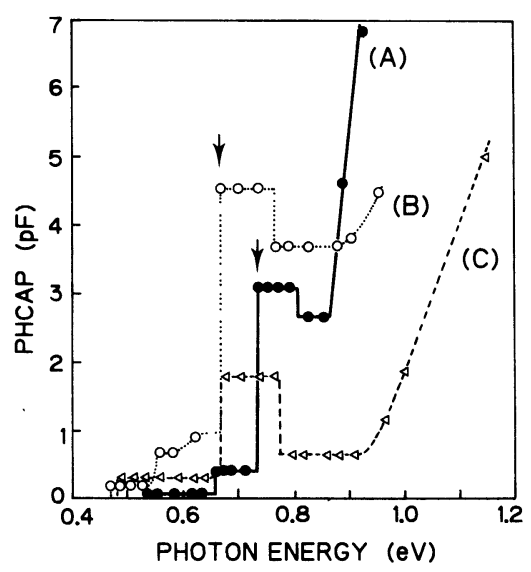

Fig. 3. - Quasi steady state photocapacitance spectra for (A) as-grown $\mathrm{HB}$ GaAs, (B) oxygen-implanted and $700{ }^{\circ} \mathrm{C} / 15 \mathrm{~min}$ annealed $\mathrm{HB}$ GaAs and (C) oxygen-implanted and $800^{\circ} \mathrm{C} / 2 \mathrm{~min}$ LPE GaAs.
As shown in the figure, large capacitance increase was observed at $0.67 \mathrm{eV}$ in the oxygen-implanted samples, both HB and LPE, while in the as-grown $\mathrm{HB}$ wafer, it was at $0.74 \mathrm{eV}$, as marked by the arrows. Therefore, these levels are different even though the thermal emission rates are similar. Ion implantation of other species such as nitrogen and gallium also creates EL2-O, which has the same photocapacitance threshold energy at $0.67 \mathrm{eV}$ [18]. The possibility is, therefore, excluded that oxygen impurity is the origin of EL2-O. A smaller increase of capacitance at $0.67 \mathrm{eV}$ was also observed in the as-grown HB GaAs. This increase means that EL2-O is also contained in as-grown HB GaAs. LEC GaAs shows a similar spectrum; there exist two types of traps which have the photoionization threshold at 0.67 and $0.74 \mathrm{eV}$, respectively. However, in the case of LEC samples, increase at $0.67 \mathrm{eV}$ was the major portion in contrast to the result for $\mathrm{HB}$ GaAs. Similar results of existence of two types of midgap levels is also found in a VPE GaAs layer [19].

2.2 Photoquenching EFFECT. - A peculiar optical characteristic called the photoquenching effect has been observed for EL2. Photocapacitance $[5,20]$, absorption coefficient [21] or luminescence intensity [22] decreases under illumination $(h \nu=1.1 \mathrm{eV})$ at low temperatures. This effect is explained by a transformation of EL2 centers to their metastable states. Several models have been so far reported for this metastability. They can be actually classified into two categories; the model based on a large lattice relaxation at the metastable state [20] and one on the Coulombic interactions [23].

In this section, a variation in the transition characteristics between the normal and metastable states of the EL2 family is discussed.

Table I. - List of the samples used in the study.

\begin{tabular}{|c|c|c|c|}
\hline Sample & Midgap level & $n\left(\mathrm{~cm}^{-3}\right)$ & Growth conditions etc... \\
\hline LEC1(T) & ETX-1 & $0.8 \sim 1.7 \times 10^{16}$ & undoped, $\mathrm{SiO}_{2}$ cruicible \\
\hline LEC2(F) & ETX-4 & $0.3 \times 10^{16}$ & $\begin{array}{l}\text { undoped, } \mathrm{pBN} \text { cruicible, } \\
\text { grown from poly crystalline GaAs }\end{array}$ \\
\hline $\mathrm{HB}$ & EL2 & $1.6 \times 10^{16}$ & undoped, $\mathrm{SiO}_{2}$ boat \\
\hline VPE & EL2 & $2.5 \times 10^{15}$ & grown on $\mathrm{n}^{+}$-substrate \\
\hline LPE & EL2-O & $1 \times 10^{16}$ & $\begin{array}{l}\text { undoped, } \mathrm{O}^{+} \text {implantation at } 100 \mathrm{keV} / 1 \times 10^{13} \mathrm{~cm}^{-2} \text {, } \\
\text { annealed at } 600{ }^{\circ} \mathrm{C} \text { for } 15 \mathrm{~min}\end{array}$ \\
\hline MOCVD & EL2 & $1.5 \times 10^{15}$ & $\begin{array}{l}\text { undoped grown on } \mathrm{n}^{+} \text {-substrate } \\
\qquad T_{\text {sub }}=720^{\circ} \mathrm{C}, \mathrm{V} / \mathrm{III}=20\end{array}$ \\
\hline
\end{tabular}


2.2.1 Transition from the normal state to the metastable state. - First, a variation in the photoquenching transients and photoquenching spectra at EL2 centers in various $\mathrm{GaAs}$ crystals are reproduced in figures $4 a$ and $4 b$, which were reported by Taniguchi and Ikoma [14]. The samples studied are listed in table $I$ and the midgap levels in respective samples are also labeled. Main features in figure $4 \mathrm{~b}$ are that photoquenching rate increases at the higher energy region than $1.3 \mathrm{eV}$ for all the EL2 centers and that a variation among the EL2 family is more pronounced here than in the Gaussian region around $1.13 \mathrm{eV}$. This observation strongly suggests that the EL2 family has a variation in the energy

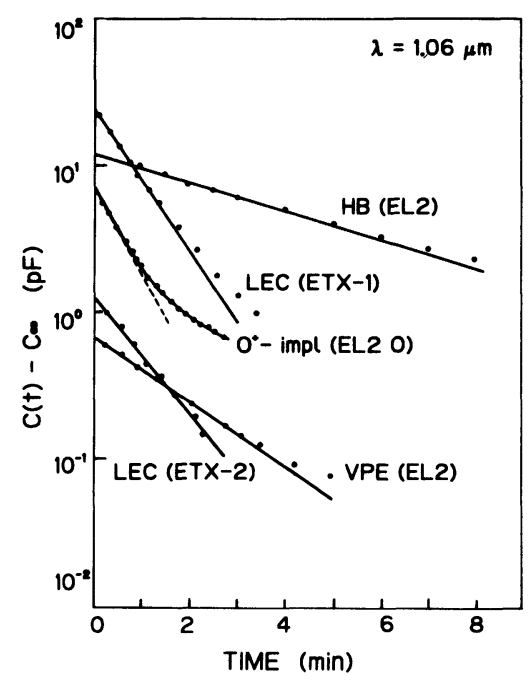

a)

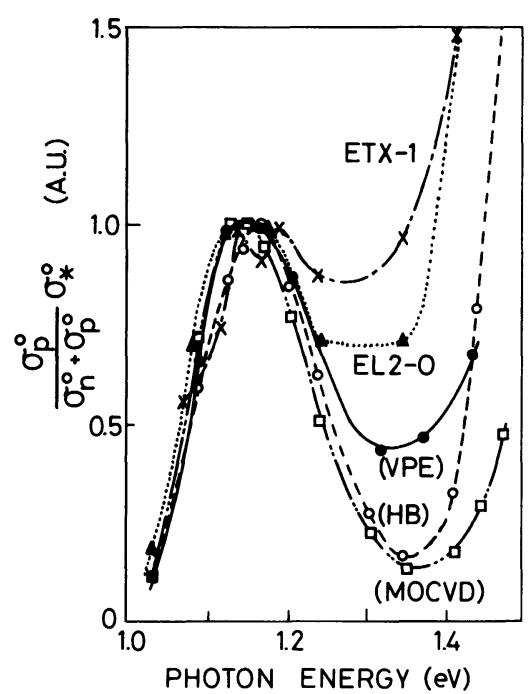

b)

Fig. 4. - (a) Capacitance transients due to photocapacitance at the EL2 family in various GaAs crystals. (b) Photoquenching spectra for the EL2 family. Peak heights are normalized to the values at $1.12 \mathrm{eV}$. configuration between the normal and the metastable states.

This point is actually explored more in detail for the case of EL2 in the Czochralski (LEC) grown crystal (referred to as ETX-1). This center (as well as EL2-O in oxygen implanted and annealed LPE GaAs) readily shows a strong non-exponentiality in figure $4 a$, suggesting that similar traps with different photoquenching rates exist in this crystal. In order to eliminate the effect due to nonlinear relationship between capacitance and ionized trap density, we performed a constant capacitance measurements where the change in applied voltage, $\Delta V$, necessary to maintain the depletion layer-width constant was monitored. In this case, $\Delta V$ is expressed as

$$
\Delta V=\Delta \rho\left(V_{\mathrm{bi}}-V_{\mathrm{appl}}-k T / q\right) / N_{\mathrm{d}}
$$

where $V_{\text {bi }}, V_{\text {appl }}$ and $N_{\mathrm{d}}$ are built-in potential, applied voltage and shallow donor density, respectively. It is directly seen that the change in voltage is proportional to that in space charge density $\Delta \rho$. Figure 5a shows the result of the constant capacitance method for ETX-1 at three excitation photon energies. It is concluded that the non-exponentiality is not due to experimental error but due to the inherent property of EL2. This level may consist of traps with slightly different photoquenching rates. The resultant rate is expected to be broadened with a certain distribution. A Gaussian distribution was assumed for simplicity in the study. Figure $5 b$ displays the distributions which gave the best fits (solid curves in Fig. 5a) to the experimental transients. Values of a measure of broadening (the standard deviation normalized to the mean value, denoted as NSD) were $0.38,0.52$ and 0.69 at photon energies of $1.09,1.17$ and $1.48 \mathrm{eV}$, respectively. However, as shown in the figure these distributions of photoquenching rate tend to extend into the negative region. This has no physical meaning and may suggest that the simple Gaussian distribution is not really adequate.

Figure $6 \mathrm{a}$ shows photoquenching capacitance transients when the width of injection-pulse for recovery from the metastable to normal states is varied from $0.6 \mathrm{~ms}$ to $5 \mathrm{~min}$. When the pulse width is 5 min, all the EL2 centers change from the normal state to the metastable state by shining $1.17 \mathrm{eV}$ light, while for the $0.5 \mathrm{~ms}$, approximately $20 \%$ of the EL2 centers change from the normal to the metastable state. It is apparent that the nonexponentiality was decreased by decreasing electrical pulse width. At the same time, the slope approaches the fastest component in the case of $P_{\mathrm{w}}=5 \mathrm{~min}$. This means that centers with a larger probability for the recovery by free electron injection have larger cross sections for photoquenching. A variation in the recovery probability was actually confirmed by a 

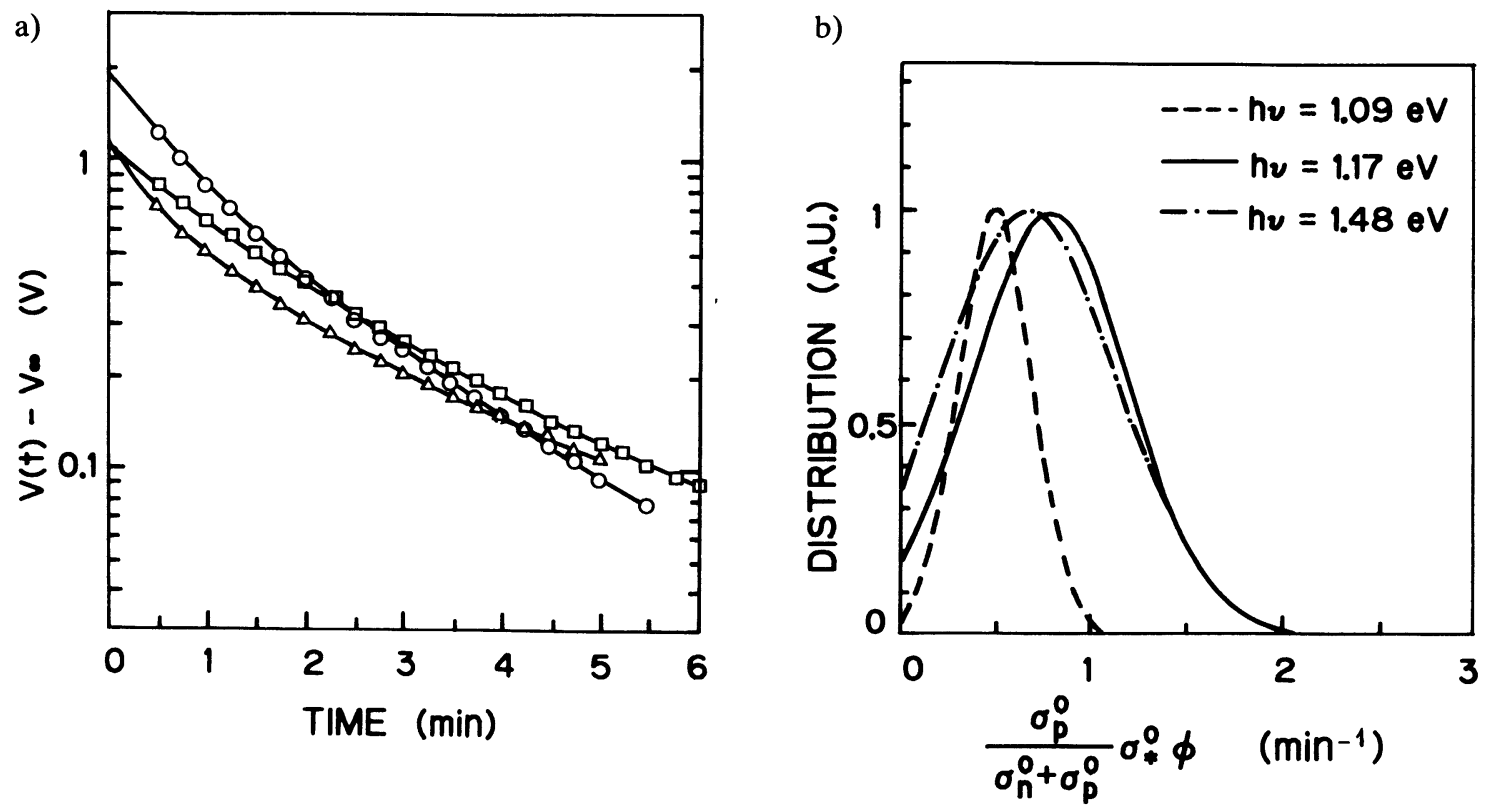

Fig. 5. - (a) Photoquenching transients measured by constant capacitance technique for ETX-1 in LEC-1(T). Excitation photon energies are $1.48(\triangle), 1.17(\mathrm{O})$ and $1.09(\square) \mathrm{eV}$. The solid curves are the calculated ones (see text). (b) Distributions of photoquenching rates used to reproduce the solid curves in (a) which give the best fit to the observed transients assuming single Gaussians.
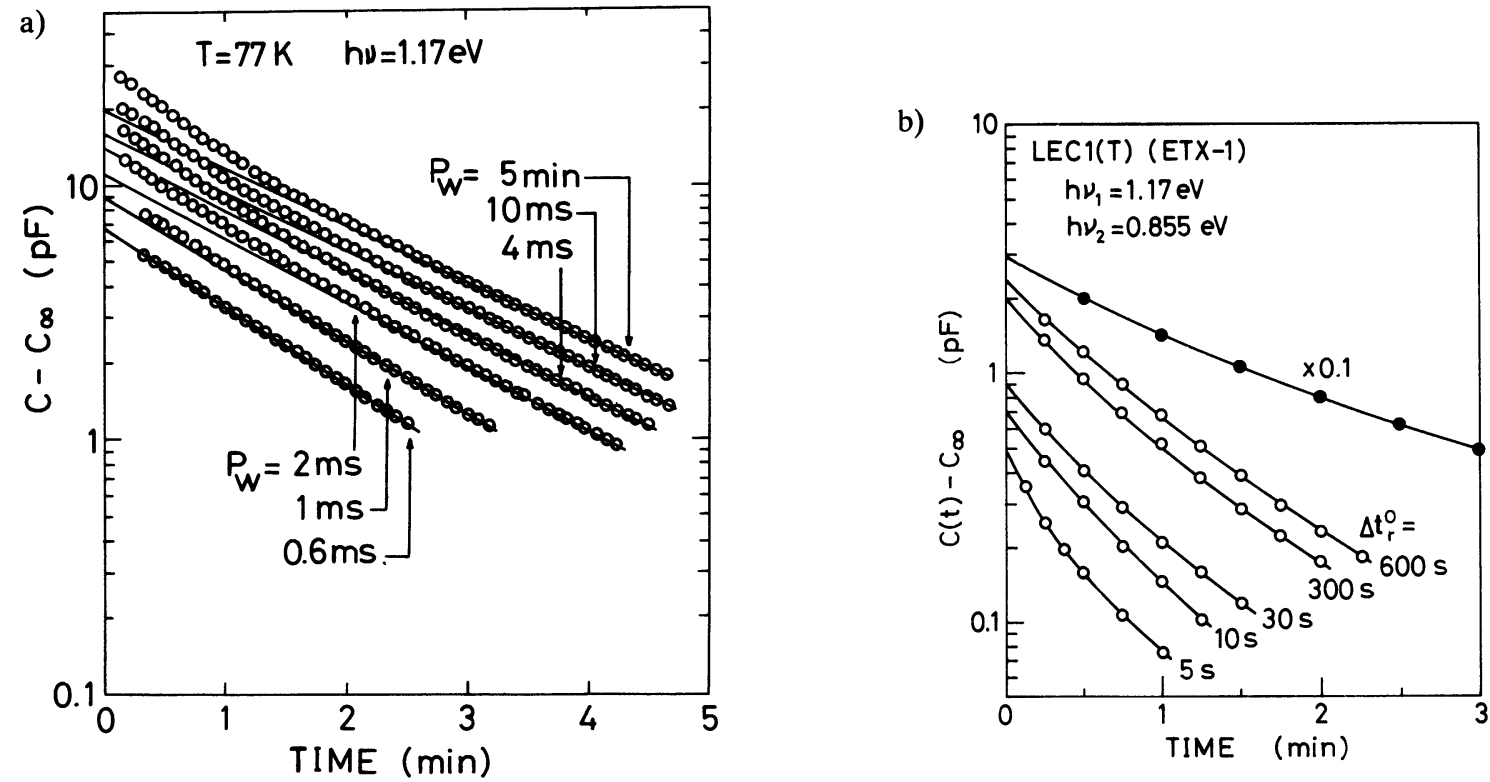

Fig. 6. - (a) Capacitance transients due photoquenching at ETX-1 after recovered to the normal state by various durations of forward bias pulse. (b) Capacitance transients due to photoquenching at ETX-1. Solid circles represent a case where all the centers are in their normal states by forward biasing. Open circles represent cases where only the levels which can be recovered by $h \nu_{2}$ illumination contribute to the photoquenching transients.

large nonexponentiality observed in the recovery transient as well.

We investigated the optical-recovery transient [24]. We can also change the recovered portion to the normal state at an isothermal condition by changing the duration of optical illumination for recovery [24]. The measurement sequence is described in the following. First, all the traps were filled with electrons and the samples were illuminated with light, $h \nu_{1}$, of $1.17 \mathrm{eV}$ which efficiently induces photoquenching. The quenched magnitude of capacitance, $C_{\mathrm{PQ}}$, corresponds to a total amount 
of EL2 in a sample. After a sufficiently long time illumination, all the EL2 centers are considered to be transferred to their metastable states. In order to study the effect of optical recovery, secondary light, $h \nu_{2}$, is sent. The number of EL2 centers which recovered to the normal state was monitored by the magnitude of photoquenching, $C_{\mathrm{r}}^{0}$, under $h \nu_{1}$ illumination. $C_{\mathrm{r}}^{0}$ is functions of $h \nu_{1}$ and the illumination period, $\Delta t_{\mathrm{r}}^{0}$

The results of optical recovery are described in the next subsection. Here, only the photoquenching transients at the recovered centers are concerned with. Open circles in figure $6 \mathrm{~b}$ shows thus obtained capacitance transients due to photoquenching at the EL2 centers which are recovered optically. The transient due to photoquenching at all the EL2 centers are also shown by solid circles for comparison. In this case, all the centers were recovered from the metastable state by forward biasing for a sufficiently long time. It is apparent from the figure that the EL2 centers which recover optically have larger photoquenching cross sections as compared to those of centers which cannot be recovered. Although this tendency is similar to the case of electrical recovery, a nonexponentiality is more pronounced for a shorter duration of illumination. Although both of electrical and optical recovery transients have large nonexponentialities, the photoquenching rates of the recovered centers are different in these recovery processes.

For studying the family characteristics of EL2, it is interesting to examine whether the broadening in photoquenching rate is photon energy dependent. If

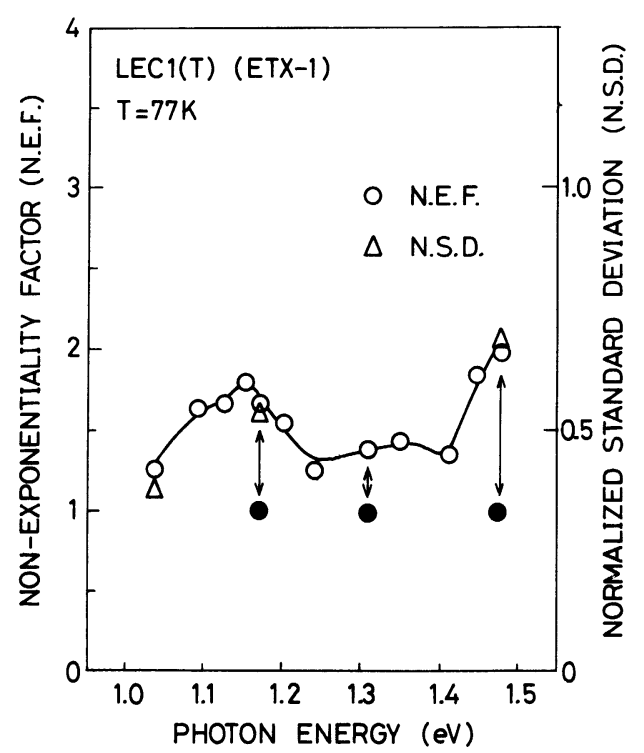

Fig. 7. - Spectral distributions of nonexponentialities (NEF) represented by open circles. Triangles correspond to the normalized standard deviation (NSD) derived from the fitting in figure $5 \mathrm{~b}$. When the recovered portion was small, NEF approaches unity (solid circles). it were independent, it could be concluded that the photoquenching rate of the midgap levels have the same spectral dependences but that only the absolute values of rates are different. Otherwise, it can be found that the spectral distributions of photoquenching rate at the midgap levels in the LEC samples are not identical. The nonexponentiality factor (NEF), which is introduced and defined as a ratio of the initial time constant to the time constant when the capacitance decreased by one decade, is shown as a function of photon energy in figure 7 . It is seen that this parameter has a nice coincidence with NSD. Therefore, the definition of the parameter is concluded to properly represent the degree of nonexponentiality. The data points in this figure correspond to the case where all the EL2 centers are recovered to the normal state prior to illumination. The main feature is the existence of a dip around $1.3 \mathrm{eV}$, which indicates that the photoquenching transient has less nonexponentiality in this energy region. When only a part of the EL2 centers are recovered, the nonexponentiality diminishes as shown by solid circles.

\subsubsection{Recovery from the metastable state to the normal state.}

a) Variation in the recovery characteristics. - All the EL2 centers are recovered from the metastable state to the normal state by raising temperature above $130 \mathrm{~K}$. This characteristic is consistent with the former observations [20]. Even for ETX-1, which showed a significant broadening in the photoquenching rate, a broadening in the recovery barrier was estimated to be smaller than $10 \mathrm{meV}$. However, as shown in figure 8, EL2-O was found to have a barrier height of $0.41 \mathrm{eV}$ which is apparently larger than those reported earlier $[20,25]$ and that for ETX-1.

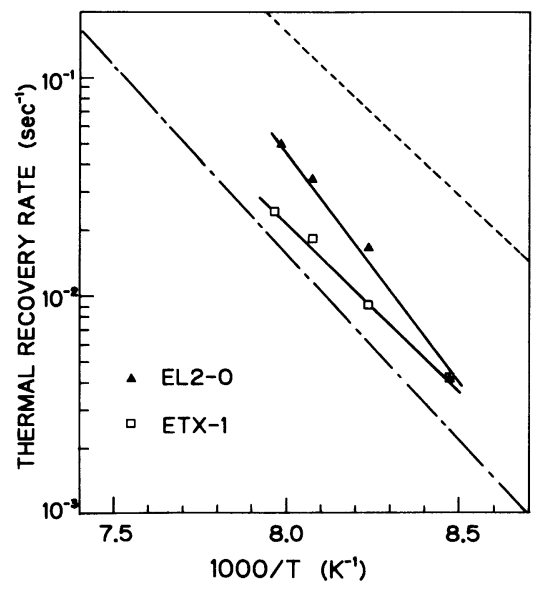

Fig. 8. - Arrhenius plots of the thermal recovery process at ETX-1 and EL2-O. Previously reported data [20, 25] are also shown. 
It was further found that the recovery process by free electron injection was not allowed at EL2-O. This is illustrated in figure 9. At the top, the illumination and the bias voltage variations are shown. The corresponding capacitance changes are shown for ETX-1 and EL2-O in the bottom half of the figure. The measurement was carried out at $77 \mathrm{~K}$. After quenching by the first illumination, forward voltage was applied for $5 \mathrm{~min}$. ETX-1 showed photoquenching by the second illumination which is exactly the same as the first one. On the

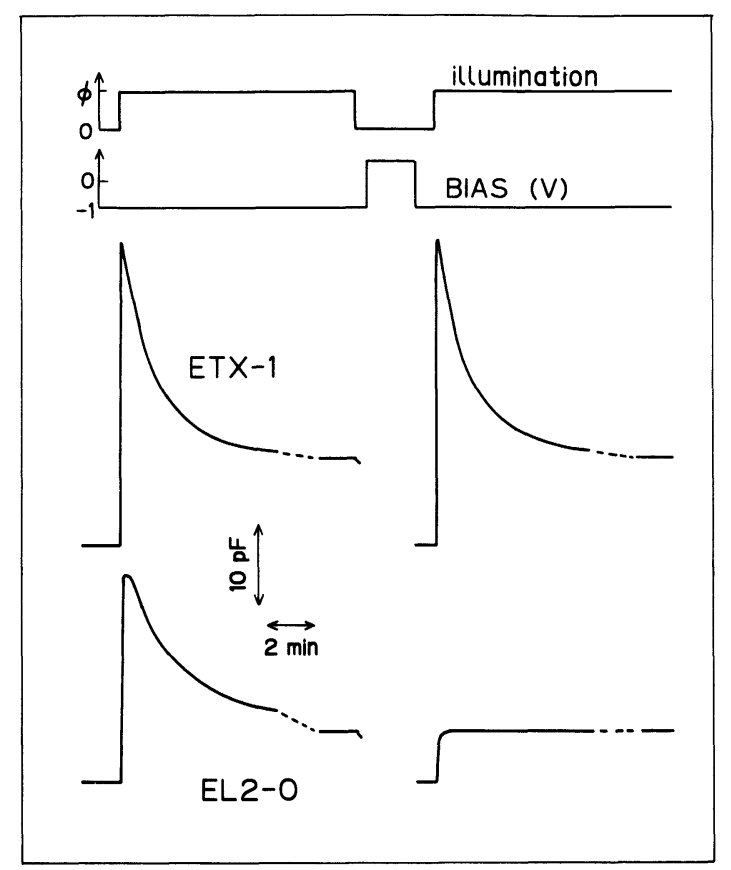

Fig. 9. - Capacitance variations of ETX-1 and EL2-O as a function of time. No recovery from the metastable state was observed by forward biasing at EL2-O. contrary, EL2-O showed no photoquenching after the forward bias, indicating no recovery took place during the forward biasing. As is well known, EL2 in HB and MOCVD GaAs showed the recovery by forward biasing. No clear explanation is given so far for the relation between thermal recovery barrier and electron injection process.

b) Optical recovery process at EL2 family. - The results of optical recovery of photoquenching are described elsewhere [24] and therefore only briefly summarized here. The optical recovery process is observed at about $10 \%$ of the total EL2 centers in LEC GaAs but neither at all in $\mathrm{HB}$ and MOCVD GaAs nor at EL2-O. The measurements were carried out at $77 \mathrm{~K}$ using Schottky barrier diodes fabricated by $\mathrm{Au}$ evaporation to various $\mathrm{n}$ type GaAs crystals. The transient of optical recovery measured at ETX-1 is shown in figure 10, in which $F_{\mathrm{r}}^{0}=C_{\mathrm{r}}^{0} / C_{\mathrm{PQ}}$ is plotted as a function of the illumination period $\Delta t_{\mathrm{r}}^{0}$. An important result is that $F_{r}^{0}$ tends to saturate and only a part of the EL2 centers can be recovered from the metastable state to the normal state by illumination. The saturation value was $8 \%$ for ETX-1 and $12 \%$ for ETX-4, which are independent of $h \nu_{2}$. This fact means that the optical recovery is allowed only at some portion of the total EL2 centers in LEC crystals. The optical recovery rate changes as the photon energy, $h \nu_{2}$ is varied. Such characteristics are common for an optical excitation process between two localized states. The transition energy can be evaluated by measuring a spectral dependence of the recovery rate. Figure 11 shows $F_{\mathrm{r}}^{0}$ as a function of $h \nu_{2}$ where $\Delta t_{\mathrm{r}}^{0}$ was fixed at $10 \mathrm{~min}$. The peaks are at $0.855 \mathrm{eV}$ with FWHM of $130 \mathrm{meV}$.

It is, therefore, concluded that the optical recovery from the metastable state to the normal state takes
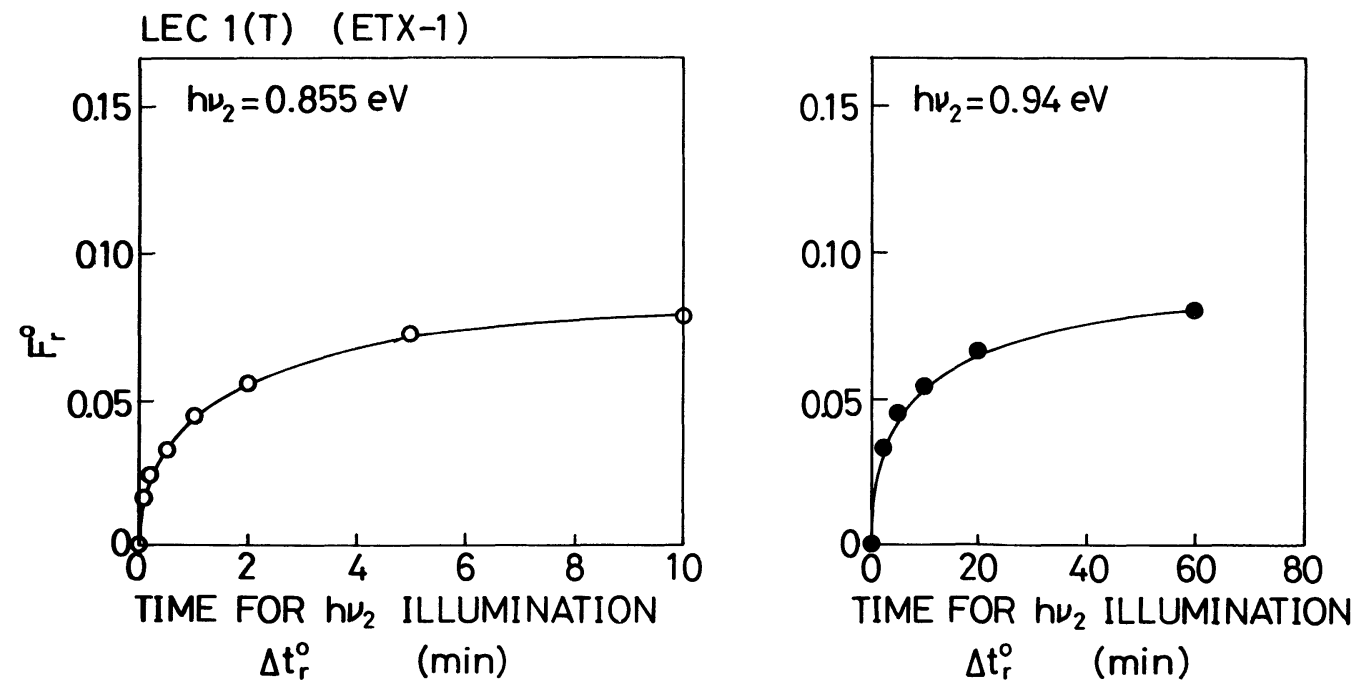

Fig. 10. - Fractional recovery $\left(F_{\mathrm{r}}^{0}=C_{\mathrm{r}}^{0} / C_{\mathrm{PQ}}\right)$ by $0.855 \mathrm{eV}$ - and $0.94 \mathrm{eV}$-light as a function of time. 


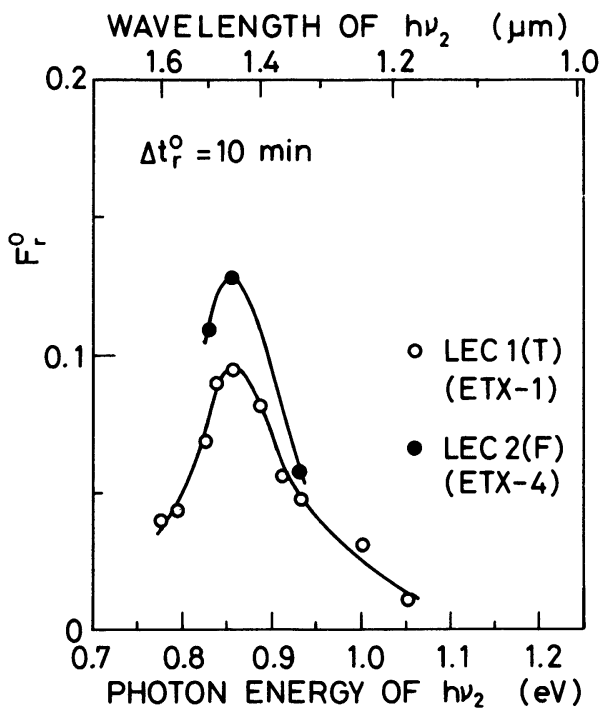

Fig. 11. - Dependence of $F_{\mathrm{r}}^{0}$ at ETX-1 (open circles) and ETX-4 (solid circles) on $h \nu_{2}$, where $\Delta t_{\mathrm{r}}^{0}$ and $h \nu_{1}$ are $10 \mathrm{~min}$ and $1.17 \mathrm{eV}$, respectively.

place only at some «members » in the EL2 « family " in LEC GaAs and that the optical transition energy $E_{\mathrm{r}}^{0}$ in the configuration coordinate scheme is $0.855 \mathrm{eV}$. The centers which recover by illumination have a microscopic structure different from those of centers which shows no optical recovery. The fact that some of the EL2 centers show the optical recovery and the rest does not indicates clearly that EL2 is no more a single well-defined level.

Using the optical recovery energy value, we can examine a validity of the configuration coordinate model for the normal and the metastable states. Assuming parabolic branches for these states which couples with the same phonon mode, the peak energy of photoquenching rate $E_{\mathrm{q}}^{0}$ and the energy barrier for thermal recovery $E_{\mathrm{r}}^{\text {th }}$ determine the relative configuration of the two states. As a consequence, $E_{\mathrm{r}}^{0}$ is predicted as the vertical distance of the metastable state and the branch of the normal state. As shown in figure $12 \mathrm{a}$, the configuration coordinate model by Vincent et al. [20] results in $E_{\mathrm{r}}^{0}$ of $1.18 \mathrm{eV}$ which is much larger than the experimental value $0.855 \mathrm{eV}$. No other choice of two energy values out of these three provides a consistent diagram [24]. It is necessary to assume different phonon frequencies at the two states, i.e. different curvatures of the parabola, for obtaining a consistent diagram. Such diagram is actually obtained as shown in figure $12 \mathrm{~b}$, where the phonon frequency for the metastable state is 1.3 times that for the normal state. However, we face an inconsistency that the metastable state is lower in energy than the normal state. Based on the above argument, the transition between the normal and metastable states at the (a)

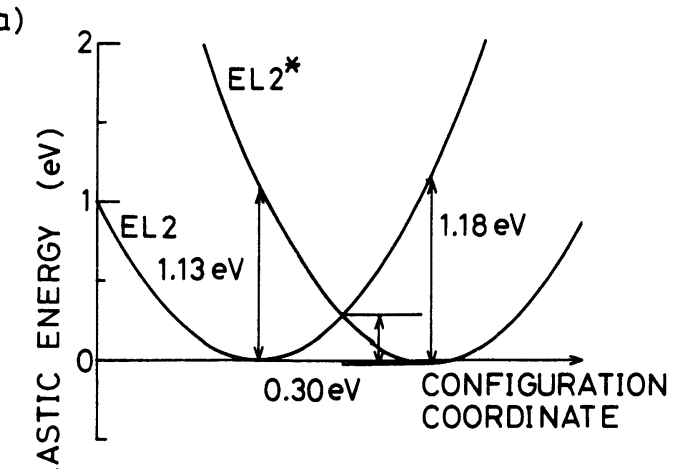

(b)

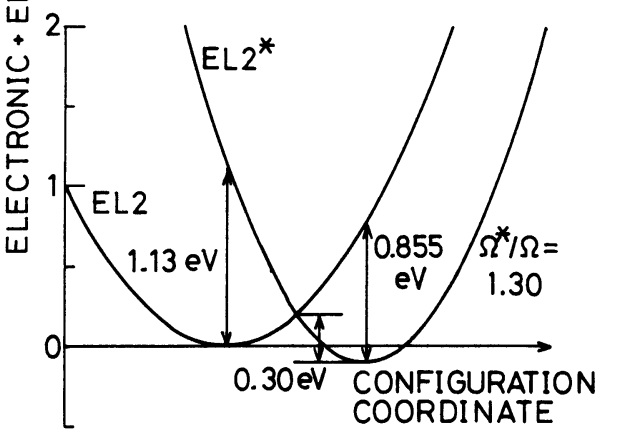

Fig. 12. - Configuration coordinate model for the normal and the metastable states of EL2. (a) shown the scheme originally proposed by Vincent et al. [20] ; (b) is the case where ratio of phonon frequencies is taken as a fitting parameter to make the three transition energies consistent.

centers which recover optically cannot be described using a simple CC model. We have to assume a more complicated scheme such as an optically-induced defect reaction which is frequently observed in amorphous materials.

c) Summary of recovery process. - The natures of the recovery processes measured at various EL2 centers are collectively tabulated in table II. Although the mechanisms for electrical and optical recovery are not clearly understood, it is apparent that the «family » characteristics do appear clearly in these recovery processes.

Table II. - Summary of the recovery characteristics from the metastable state to the normal state of the EL2 family.

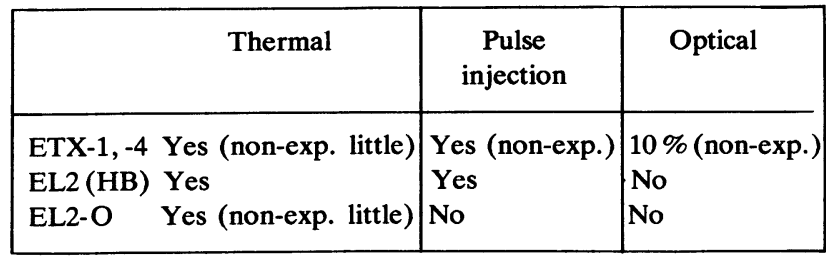

2.2.3 Discussions. - Some interpretations may be possible for the variation of the photoquenching spectra in figure $4 \mathrm{~b}$. The EL2 in HB, MOCVD or 
VPE GaAs can be regarded as a well defined center. At these centers, the photoquenching spectrum consists of a Gaussian shape spectrum (Region I) centered at $1.18 \mathrm{eV}$ and a spectrum increasing above $1.3 \mathrm{eV}$ up to the bandgap energy (Region II). The simplest interpretation for the shape of ETX-1 is that it has a broader Gaussian shape which obscure the valley. However, this model is not likely because with this model a uniform NEF distribution should be expected, being in disagreement with figure 7 . It is more advantageous to assume at least two types of centers which have slightly different photoquenching spectra as illustrated in figure 13 . One has a relatively large cross section in Region I as compared to Region II, while the other has an inverse relationship. Based on this model, the NEF spectrum in figure 7 is interpreted as a superposition of two different photoquenching rates. The dip around $1.3 \mathrm{eV}$ is expected because the values of quenching cross sections of the two centers become similar around $1.3 \mathrm{eV}$.

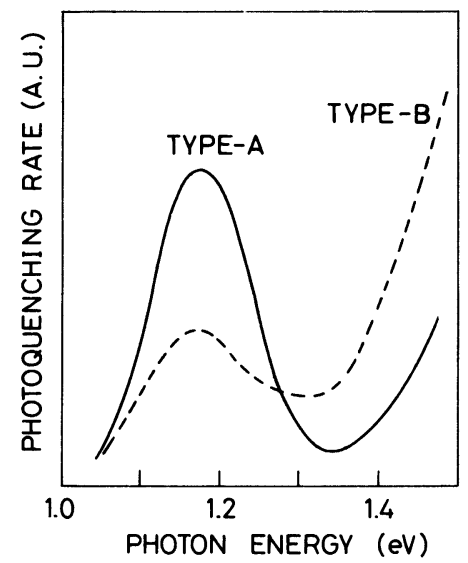

Fig. 13. - An illustration of two types of EL2 centers assumed to explain the spectral distribution of NEF at ETX-1 in figure 7.

The Type-A center in figure 13 shows a similar photoquenching spectrum to that for EL2 in HB or MOCVD crystal. However, it should be reminded that EL2 which recovers optically from the metastable state has a larger quenching rate than that of EL2 at which this recovery process is not allowed. This result claims that EL2 which recovers optically belongs to Type-A because this type has a larger photoquenching rate at $1.17 \mathrm{eV}$. It is concluded, therefore, that not all of the Type-A EL2 in LEC GaAs can be regarded as identical centers to those in HB or MOCVD GaAs. This conclusion leads to an existence of more than three types of EL2 centers in GaAs at least according to the aforementioned basic classification.
2.3 ZERO PHONON TRANSITION TO THE EXCITED STATE. - After Kaminska et al. [6] reported the intracenter absorption at EL2, characteristics of the excited state have been intensively explored. In our previous papers [26, 27], we clarified the optical transition mechanisms at EL2 using a novel Spectral Photocapacitance Transient Analysis (SPTA) technique as well as the experimental evidences reported so far. The SPTA technique clearly revealed the role of the excited state in the charge transfer to the metastable state. In this paper, we will shed light on the fine structures in photoquenching rate spectra obtained by the SPTA technique. A variation in the SPTA spectra was again observed in various $\mathrm{GaAs}$ crystals.

2.3.1 General features of SPTA spectra. - SPTA is a modified version of photocapacitance measurement. In the SPTA measurement, excitation photon energy is slowly scanned and a local derivative of capacitance transient due to photoquenching is measured with a micro-computer controlled system. As a result, either photoionization or photoquenching rate spectrum can be obtained with a very fine resolution. Additional advantage over the absorption measurement is the applicability to thin epitaxial films since the measurement accesses the depletion region.

The result is shown in figure 14. Besides the Gaussian spectrum, a fine oscillatory structure is observed at 1.03 to $1.08 \mathrm{eV}$. The first sharp peak is located at $1.039 \mathrm{eV}$ followed by an oscillation with an interval of approximately $11 \mathrm{meV}$ at the higher energy side. The feature is similar to the fine structures observed in the intracenter absorption, where the zero-phonon line (ZPL) is at $1.039 \mathrm{eV}$ and the separation of phonon replica is $11 \mathrm{meV}$. Therefore, it can be concluded from such a similarity that the zero-phonon transition and its interaction with phonon(s) are also observed in the SPTA spectra.

Further information of significant importance is obtained from the SPTA spectrum. It should be noted that the ZPL in the SPTA spectrum at $1.039 \mathrm{eV}$ has a negative peak. Since the transition rate in figure 14 corresponds to an increasing rate of negative charge in the space charge region, the ZPL transition indicates a decrease of negative charge, which does not mean an enhancement of photoquenching as pointed out by Kaminska et al. [6]. This result positively identifies that the ZPL transition acts as a path for electrons to relax to the conduction band.

2.3.2 Sample dependence. - A family nature of EL2 revealed in the SPTA spectra was studied by comparing the results measured in different GaAs crystals. Figure 15 compares the fine structures measured in MOCVD and LEC GaAs. It has been found that EL2 in LEC GaAs exhibits a broader 


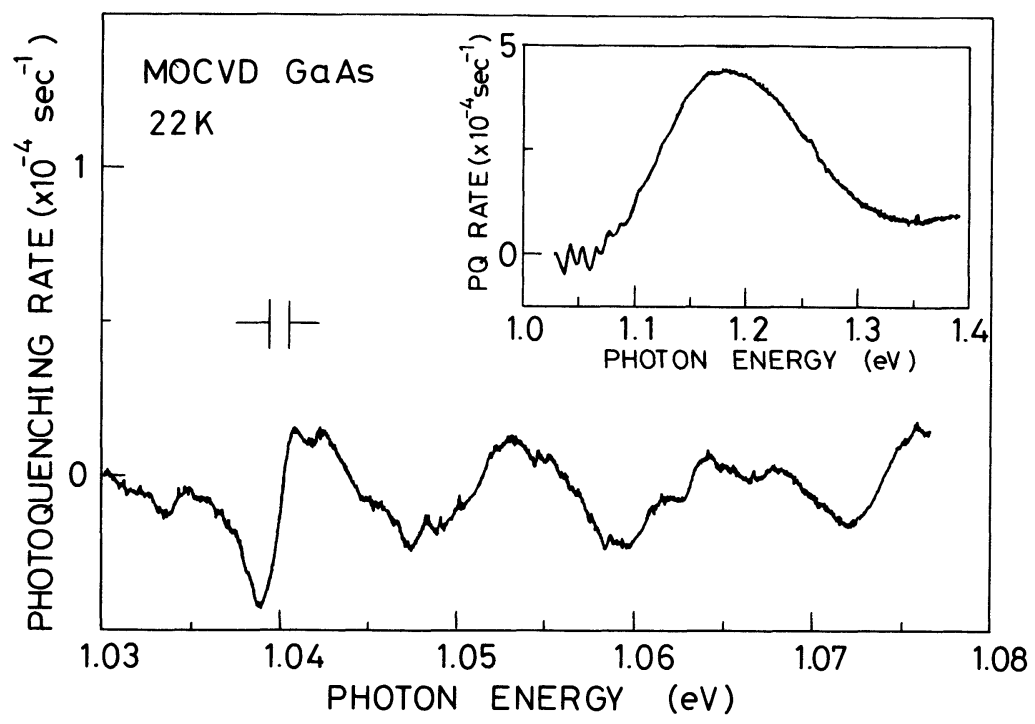

Fig. 14. - The SPTA spectrum of photoquenching rate measured with a high resolution. The inset shows the overall SPTA spectrum.

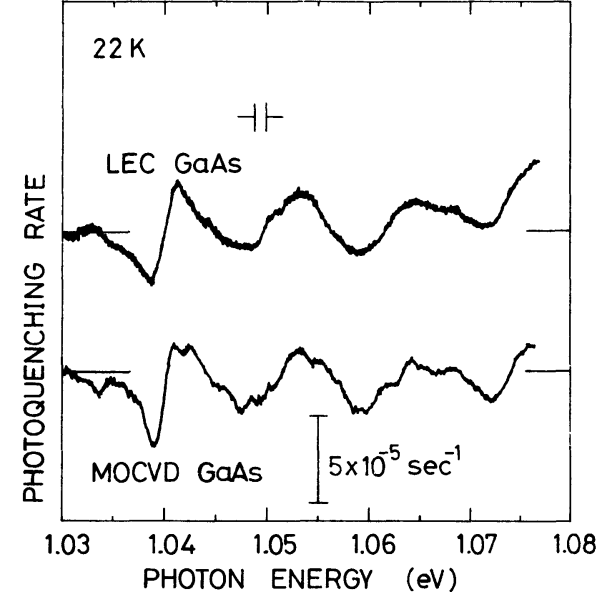

Fig. 15. - Comparison of the fine structures in the SPTA spectra for EL2 in different GaAs crystals.

spectrum than that of EL2 in MOCVD GaAs. The FWHM of ZPL in LEC GaAs is $3.6 \mathrm{meV}$, while it is $1.9 \mathrm{meV}$ in MOCVD GaAs.

A broadening of the Gaussian spectrum in LEC GaAs is observed in the SPTA, being consistent with point-by-point measurement [14], in which the nonexponentiality is larger in LEC GaAs than in MOCVD GaAs indicating that a variation among the EL2 family in LEC crystals is larger than that in MOCVD GaAs. The SPTA spectrum is deviated from the Gaussian and again consistent with the previous result that a double-peak spectrum was observed at some of the EL2 in LEC GaAs. It also seems reasonable that the ZPL for LEC GaAs is broader than that for MOCVD GaAs. This is the first observation of the family nature of EL2 in the ZPL spectra. However, it should be pointed out that the ZPL of intracenter absorption reported by Skowronski et al. [28] is not so broad as that observed by SPTA. Although the ZPL spectra of absorption cannot be attributed to a single optical transition line but a convolution of two (or more) lines, the FWHM is much less than the value for the SPTA result.

The reason for this discrepancy is explained as follows. In LEC GaAs, the EL2 centers are sizable point defects and may have slightly modified atomic structures to each other. Although the main characteristic such as a ZPL transition to the excited state is common due to a common involvement of a certain defect, a variation in the additional defect may cause a slight change in the energy splitting between the ground and the excited states. Such a scheme is consistent with the larger variation observed in LEC GaAs rather than that in MOCVD GaAs. At a more distorted center, the transition probability to the excited state should be smaller. A rapid decrease in the probability may give rise to a rather sharp ZPL which has been observed in intracenter absorption. However, the lattice relaxation may also change, which would enhance a probability of electron transfer from the excited state to the conduction band. This enhancement may cause a more pronounced broadening in SPTA spectra, since this method monitors the overall transfer rate to the final state, i.e. to the conduction band.

\section{Stability of members of EL2 family.}

In this section, effects of damages introduced by heavy particle bombardment on EL2 natures are discussed. Change of EL2 is studied after GaAs crystals are subjected to ion implantation or reactive 
ion etching (RIE) processes. The results indicate a sensitivity of EL2 to creation of damages suggesting that EL2 originates from a sizable defect.

3.1 ION IMPLANTATION AND ANNEALING. - EL2 in as-grown $\mathrm{HB}$ GaAs crystal is annihilated by ion implantation. Figure 16 shows the change of deep levels after oxygen ion implantation (dose : $1 \times 10^{13} \mathrm{~cm}^{-2}$ ) into an HB GaAs sample and successive annealing. Au Schottky electrodes were employed for DLTS measurements. After implantation, EL2 detected in as-grown crystal was completely vanished due to the implantation damage. Annealed at $400{ }^{\circ} \mathrm{C}$, a rather broad peak appeared around $360 \mathrm{~K}$ and this peak became larger and narrower as the annealing temperature was increased, while all the peaks of other electron traps decreased. In the $700{ }^{\circ} \mathrm{C}$ annealed sample one peak became dominant. Since this midgap level shows the photoquenching effect, this level is regarded to belong to the EL2 family (EL2-O). However, as shown in the previous section, several characteristics of this level are apparently different from those of EL2 originally found in bulk materials, especially on the photoionization threshold energy and the recovery characteristics from the metastable state.
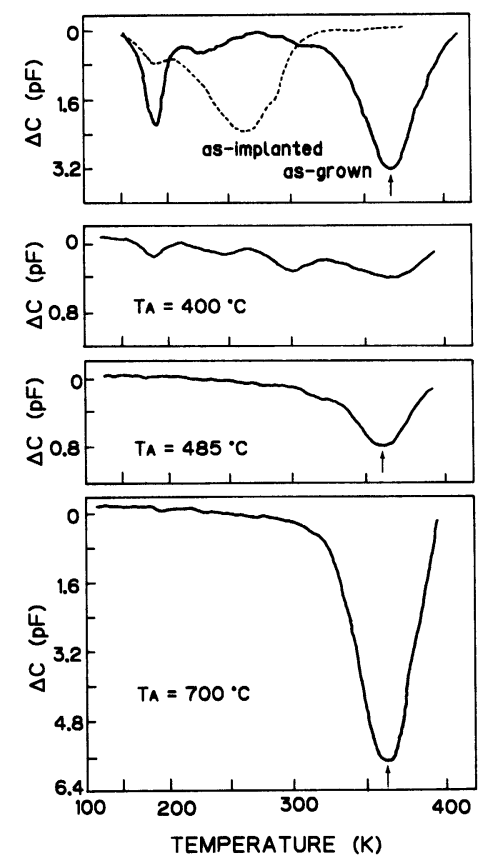

Fig. 16. - Change of DLTS spectra with annealing time in oxygen implanted HB GaAs. For reference, the DLTS spectrum in as-grown $\mathrm{HB}$ GaAs is included.

Stability of implantation induced midgap level, EL2-O, is also studied by DLTS. In figure 17, peak height of EL2-O in DLTS spectra are plotted as a function of annealing time at $600{ }^{\circ} \mathrm{C}$. The crystal was an undoped n-type LPE layer to which oxygen

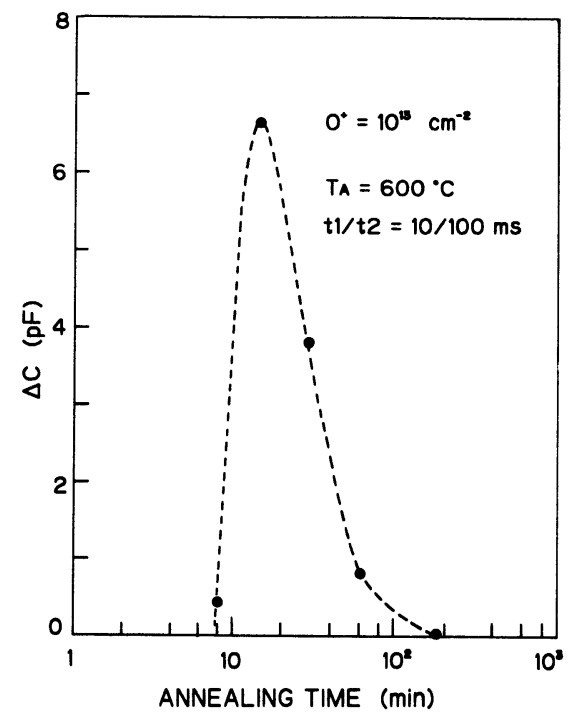

Fig. 17. - Change of DLTS peak height with annealing time in oxygen implanted LPE GaAs. The annealing temperature is $600^{\circ} \mathrm{C}$.

implantation was performed. After 15 min annealing the peak became maximum and almost disappeared after $20 \mathrm{~min}$. The density at its maximum was $1.1 \times 10^{16} \mathrm{~cm}^{-3}$ and had an LSS-like distribution. Figure 18 shows the bias voltage dependence of the peak height annealed at different conditions. An LSS-like distribution observed after $600^{\circ} \mathrm{C} / 15 \mathrm{~min}$ annealing suggests that the creation of EL2-O by post-implantation annealing is closely correlated with damage introduced by the implantation process.

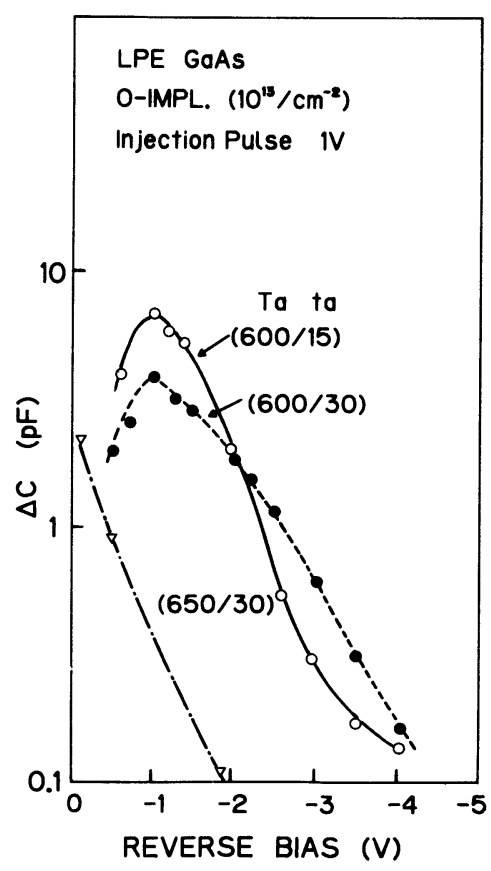

Fig. 18. - Change of DLTS peak height with bias voltage in three samples annealed at different temperatures $\left(T_{\mathrm{A}}\right)$ and periods $\left(t_{\mathrm{A}}\right)$. 
Since the results were similar by changing the implanted species such as nitrogen, gallium and arsenic, it is not likely that an involvement of the implanted species is essential for the creation of EL2-O.

Distribution of EL2-O after $650^{\circ} \mathrm{C} / 30 \mathrm{~min}$ in figure 18 may coincide with the anneal-out of lattice defects by the implantation process. After a longer time $\left(100 \mathrm{~min}\right.$ at $600{ }^{\circ} \mathrm{C}$, for instance) or a higher temperature annealing $\left(700{ }^{\circ} \mathrm{C}\right.$ for $15 \mathrm{~min}$, for instance), the peak was not detected. This result indicates that EL2-O is rather unstable in this temperature range. This level is related to the intermediate stage of defect annealing. Usual electrical activation of implanted impurities is classified into two stages; (1) anneal-out of lattice defects introduced by bombardment, which occurs around $600{ }^{\circ} \mathrm{C}$ and (2) anneal-out of point defects and siteoccupation by impurity atoms, which occur around $800^{\circ} \mathrm{C}$. The appearance of EL2-O is in accordance with the stage-(1). Thus, EL2-O is more likely to be a sizable defect created during the defect migration than a simple point defect.

\subsection{ANNIHILATION OF EL2 BY REACTIVE ION ETCH-} ING (RIE). - In the ion implantation process, damages introduced are so large as to disturb the host lattice structure. During RIE process, a sample is also subjected to heavy particle bombardment by plasma. However, in this case, damage is far less and we can obtain a rather nice Schottky barrier even at the as-etched state. This situation makes a more accurate characterization of deep levels possible.

a) Experimental. - The wafers used in the study were undoped n-type $\mathrm{HB}$ GaAs. First, $\mathrm{SiO}_{2}$ $(400 \mathrm{~nm})$ was deposited by plasma-assisted chemical vapor deposition on the surface of the wafers. Prior to etching, Ohmic electrodes were formed on the backside by evaporating $\mathrm{AuGe} / \mathrm{Ni} / \mathrm{Au}$ and alloying at $400{ }^{\circ} \mathrm{C}, 5 \mathrm{~min}$. After the patterning of Schottky electrodes, $\mathrm{SiO}_{2}$ was etched by $\mathrm{RIE}$. The etching ambient was $\mathrm{CHF}_{3}$ at the pressure of 0.08 Torr and the input power was $3.5 \mathrm{~W} / \mathrm{cm}^{2}$. Then the wafer was wet-etched with a solution of $\mathrm{HF}: \mathrm{NH}_{4} \mathrm{~F}=1: 6$ for $1 \mathrm{~min}$. Schottky electrodes were formed by vacuum evaporation of Au with a thickness of $200 \mathrm{~nm}$. For reference, Schottky diodes without RIE were fabricated. In this case, $\mathrm{SiO}_{2}$ was etched by a solution of $\mathrm{HF}: \mathrm{NH}_{4} \mathrm{~F}=1: 6$ for $1 \mathrm{~min}$. It was found that $\mathrm{Au}-$ Schottky electrodes on RIE-etched wafers are easily peeled off, which is likely to be due to the degradation of dry-etched surface. However, $\mathrm{Au}$ is suitable for characterization of midgap traps due to a large barrier height of a Schottky diode. Barrier height is required to be larger than the energy level of a trap when a junction capacitance method is adopted.
Characterization of the diodes was carried out by $I-V, C-V$ and TDS-ICTS [29] measurements. $C-V$ profiling of deep levels was also performed by controlling delay time for $C-V$ profiling.

b) Results and discussions. - From the $I-V$ characteristics, it was revealed that the barrier height is lower and the saturation current is larger for RIE samples. In these samples, the extrapolated barrier height from $C-V$ measurement is largely shifted which may be due to the reduction of $N_{\mathrm{D}}-N_{\mathrm{A}}$ near the surface regions. Therefore, the dry-etched samples have poorer Schottky characteristics than that of the wet-etched samples. However, barrier height of RIE samples fall in the region $0.82 \pm 0.04 \mathrm{eV}$, which is high enough for the characterization of EL2 whose energy level is $E_{\mathrm{c}}-0.74 \mathrm{eV}$.

In the wet-etched samples EL2 was the dominant electron trap, whose emission time constant at room temperature was $23 \pm 2 \mathrm{~s}$ and concentration was $2.7-4.4 \times 10^{16} \mathrm{~cm}^{-3}$, respectively. The variation in the emission time constant is attributed to that in temperature as well as noise in the measured EL2 spectra. The spectral shapes of EL2 agreed well in general with those reproduced from a calculation assuming a single level. The observed EL2 concentrations are reasonable values in $\mathrm{HB}$ GaAs crystals.

On the other hand, no apparent EL2 signal was observed in the TDS-ICTS spectra near the surface regions of dry-etched samples as shown in figure 19(a) which was measured at the bias voltage of $-1 \mathrm{~V}$. Instead, a broad signal around $20 \mathrm{~ms}$ and a very slow transient which extends to $500 \mathrm{~s}$ were observed. DLTS measurements revealed that the former can be identified as a trap called ED5 [30], which has an activation energy $E_{\mathrm{a}}=0.51 \mathrm{eV}$. It is most likely that this level is closely related to the damage introduced by the RIE process. The origin of the latter transient is not known at present. In the deeper regions, ED5 signal was much reduced and EL2 became the dominant signal as shown in figure $19 \mathrm{~b}$. The unidentified slow transient was still observed. These results indicate that ED5 decreases while EL2 increases toward inside in the RIE processed sample.

To examine the spatial variation more in detail, $C$ $V$ profiling method was applied. Broken curve in figure 20a shows the profile of EL2 concentration in the wet-etched sample, which was derived from the $C-V$ measurements of $t_{\mathrm{d}}=10 \mathrm{~ms}$ and $t_{\mathrm{d}}=50 \mathrm{~s}$. Trap concentration $N_{\mathrm{T}}$ was calculated using a relation

$$
N_{\mathrm{T}}(W-\lambda)=\frac{1}{1-\frac{\lambda}{W}}\left\{\frac{2 \varepsilon_{\mathrm{S}}}{q}\left[-\frac{\mathrm{d} W^{2}}{\mathrm{~d} V}\right]^{-1}-N_{\mathrm{D}}\right\}
$$

Here, $\lambda$ is the distance between the depletion layer 


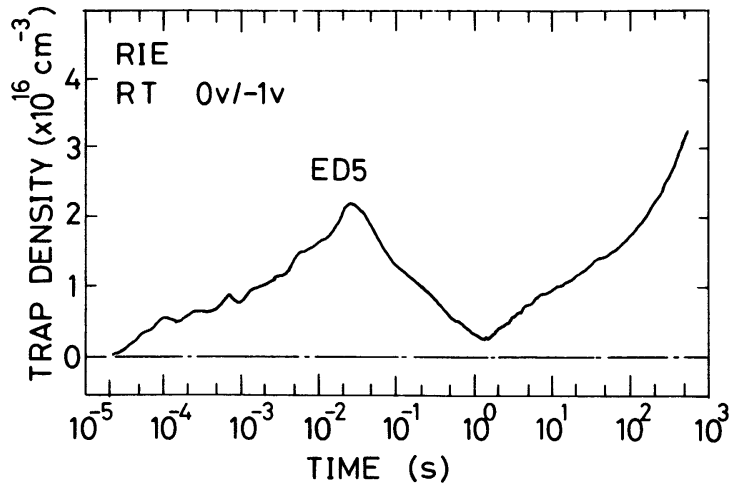

a)

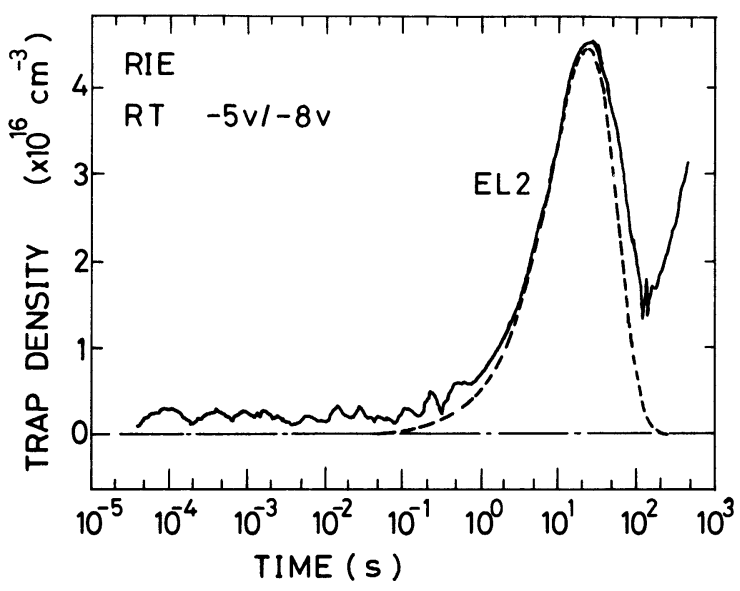

b)

Fig. 19. - TDS-ICTS spectra for the reactive ion etched sample at room temperature. The bias conditions are (a) $0 \mathrm{~V} /-1 \mathrm{~V}$ and (b) $-5 \mathrm{~V} /-8 \mathrm{~V}$.

edge and the point at which trap level and the bulk Fermi level crosses. It is seen that the EL2 concentration in bulk GaAs is almost constant along distance from the surface. However, EL2 concentration in the dry-etched samples were greatly reduced near the surface as shown in figure 20(b). In this case, $C-V$ measurements with $t_{\mathrm{d}}=1 \mathrm{~s}$ and $t_{\mathrm{d}}=50 \mathrm{~s}$ were carried out to obtain the trap profiles for ED5 and EL2 separately. Since the energy level of ED5 is unknown, $\lambda$ was calculated using the activation energy $0.52 \mathrm{eV}$ of this level, which corresponds to the estimation of the maximum concentration of ED5. In the surface region, ED5 prevails EL2 and rapidly decreases toward inside. Furthermore, a gradual increase of EL2 toward inside was observed. Although a slow ionization co-exists which cannot be attributed to the emission from EL2, $C-V$ measurement with $t_{\mathrm{d}}=50 \mathrm{~s}$ dominantly monitors the ionized EL2 centers.

The profiling method of deep levels clearly revealed that the annihilation of EL2 has a nice spatial correlation with the creation of the damage-induced level, ED5, as can be seen in figure $20 \mathrm{~b}$. It is

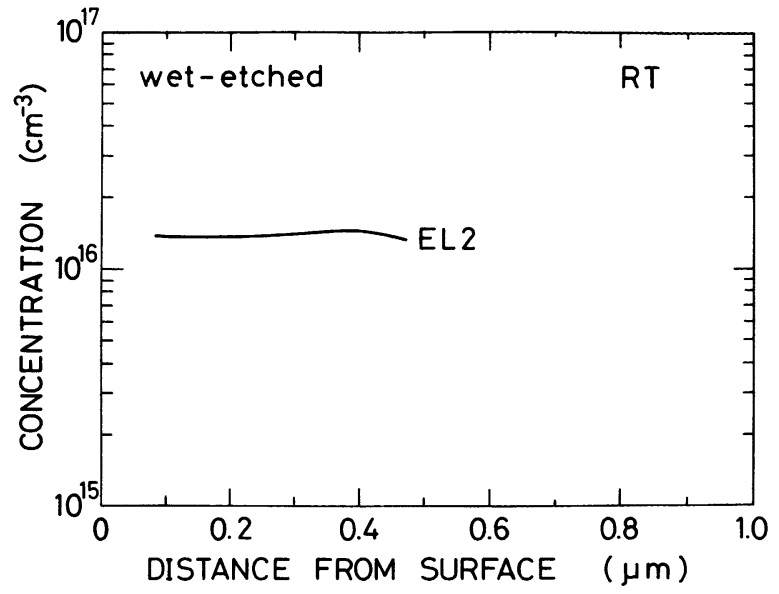

a)

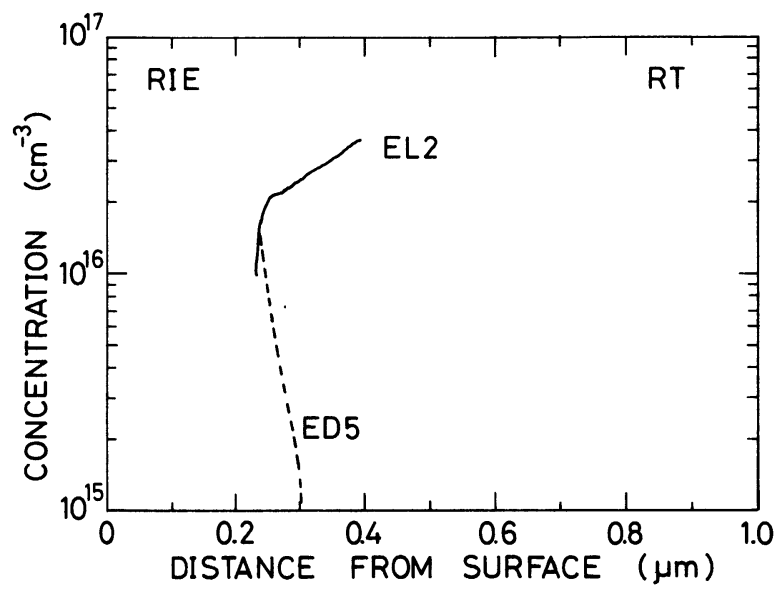

b)

Fig. 20. - Profiles of the trap concentrations for (a) the reference sample and (b) the RIE-processed sample.

concluded that EL2 centers are annihilated by a bombardment damage which is introduced to the depth of $0.2 \mu \mathrm{m}$. This characteristic depth agrees with that observed in $\mathrm{WSi}_{x} / \mathrm{GaAs}$ system [30] where metal deposition was carried out by RF sputtering. In this case, ED5 was also introduced to a depth of $0.2 \mu \mathrm{m}$ and reduction of EL2 was observed. During a sputtering process, a wafer is subjected to plasma bombardment similarly to the situation for RIE.

In both cases, the defect structure of EL2 centers are recovered after a low temperature annealing around $300^{\circ} \mathrm{C}$. In the $\mathrm{WSi}_{x} / \mathrm{GaAs}$ Schottky diodes fabricated by sputtering, EL2 concentration, which was reduced after the deposition, increased by a factor of 1.6 after $324^{\circ} \mathrm{C}$ annealing, Peak temperature in DLTS spectrum approached that of EL2 in as-grown GaAs wafers and the spectra became sharper. Although the increased amount is small, reconstruction of the EL2 centers by such a low temperature annealing was confirmed. EL2 in the dry-etched samples were also recovered to the original concentration after $350{ }^{\circ} \mathrm{C}$ annealing. These 
results provide evidence that the defect component of EL2 is highly mobile even at low temperatures. This is one of the reasons why we conclude that an interstitial, such as $A s_{I}$, rather than a vacancy defect should be responsible for EL2 formation.

It is not possible so far as to attribute ED5 as a directly transformed defect from EL2, although ED5 has a complementary profile to that of EL2. Originally, no EL2 was detected in the VPE samples probably due to the large electron concentration [31], whereas a large concentration of ED5 was introduced by RIE. Measurements were carried out on RIE-etched n-type VPE GaAs $\left(n=2 \times 10^{17} \mathrm{~cm}^{-3}\right)$. In this case, no EL2 was detected in both unprocessed and dry-etched layers. However, a damage-induced level, ED5 was again observed in the surface region of the dry-etched sample as shown in figure 21 . The concentration of ED5 seems to have a correlation with the original free electron concentration. Therefore, this defect is more likely to be assigned as a displaced shallow donor impurity or a complex of shallow donor impurity with a native defect produced by the bombardment damage. Anyhow, identification of ED5 is beyond the scope of the present paper and not discussed further.

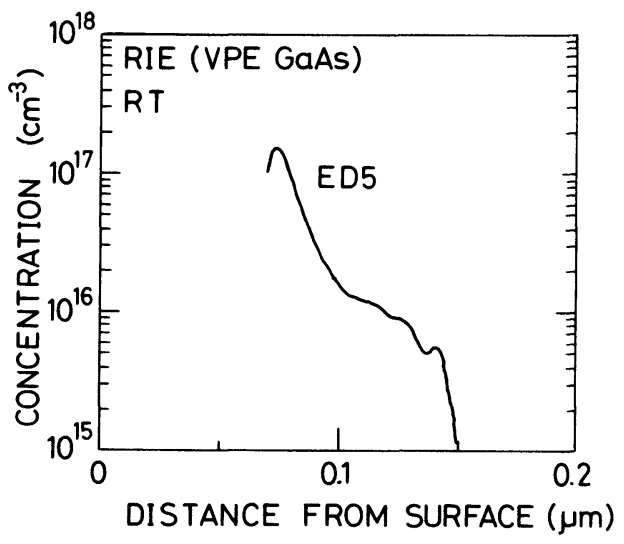

Fig. 21. - Profile of ED5 concentration in RIE-processed VPE GaAs.

\section{A model for the atomic structure of EL2 family}

4.1 As CLUSTER MODEL. - Recent assessment is that EL2 is closely related to the excess arsenic conditions. A model for the atomic structure is required to successfully explain the experimental facts which are summarized as follows ;

(i) EL2 appears during an intermediate stage of annealing after heavy particle bombardment such as ion implantation.

(ii) EL2 easily dissociates by the sputtering or dry etching damage and recovers its structure after a low temperature annealing as low as $300^{\circ} \mathrm{C}$. (iii) The trap parameters of EL2 havè variations so as to form a family of levels (EL2 family).

(iv) A large metastable relaxation takes place at EL2, which is beyond the harmonic oscillator approximation. Furthermore, the energy configuration of the normal state and the metastable state is not uniquely determined.

(v) The defect responsible for EL2 consists of a rigid point defect like $\mathrm{As}_{\mathrm{Ga}}$ and an easily displaced defect which mainly contributes to the metastability.

Details are not described concerning (v) since the results have been obtained not from the family characteristics of EL2 but from an optical characterization which has been described elsewhere [27].

Items (i) and (ii) indicate that EL2 is annihilated and created at low temperatures which is considerably lower than that for simple point defects and support the idea that EL2 should be originated from a sizable defect. Furthermore, a defect component of EL2 is required to be mobile at low temperatures as mentioned above. We speculate that $\mathrm{As}_{\mathrm{I}}$ is the most probable candidate. The trap characteristics as stated in the rest of the items also suggest that EL2 should be a sizable complex defect which enables a variation among the family. Furthermore, its bonding is likely to be «soft » so that the metastability and the family characteristics occur.

Following the item (v), the principle characteristics are likely to be determined by $\mathrm{As}_{\mathrm{Ga}}+V_{\mathrm{As}}$ or $\mathrm{As}_{\mathrm{Ga}}+\mathrm{As}_{\mathrm{I}}$. Taking into account the argument above, the latter structure is more probable. It is necessary to assume the third (or more) defect(s) to account for the results on EL2 in LEC GaAs as a consequence of the argument in section 2.2 and 2.3. It is naturally expected that $A s_{I}$ is such a defect(s). Accordingly, the atomic structure of the EL2 family can be tentatively expressed as $\mathrm{As}_{\mathrm{Ga}}+n \mathrm{As}_{\mathrm{I}}(n \geqslant 2)$. Atomic arrangement is hardly known so far but this defect can be regarded as an aggregate of more than 7 arsenic atoms. In such a phase, it is not likely that the coordinations in the host lattice are conserved.

Information on the bulk amorphous arsenic [32] gives an insight into the properties of the As-aggregate. Three-fold coordinated arsenic as shown in figure 22 is a normal configuration in amorphous arsenic. Defect states in this phase are two-fold and four-fold coordinated arsenic atoms. As can be seen in figure $22,{ }_{\mathrm{p}} \mathrm{P}_{2}^{0}$ and ${ }_{\mathrm{sp}} \mathrm{P}_{4}^{0}$ have an unpaired electron and are spin-active. (We follow the conventional notation : ${ }_{\mathrm{p}} \mathrm{P}_{2}^{0}$ means a two-fold coordinated neutral arsenic atom whose predominant type of bonding is p-like.) It is interesting to note that ${ }_{\mathrm{sp}} \mathrm{P}_{4}^{0}$ has a similar atomic configuration to an antisite arsenic $\mathrm{As}_{\mathrm{Ga}}$, corresponding to a singly ionized state $\mathrm{D}^{+}$in GaAs, which is detected by ESR measurements. According to Greaves et al. [32], furthermore, ${ }_{\mathrm{sp}} \mathrm{P}_{4}^{0}$ forms a level near the midgap in the band gap $(1.25 \mathrm{eV})$ of 

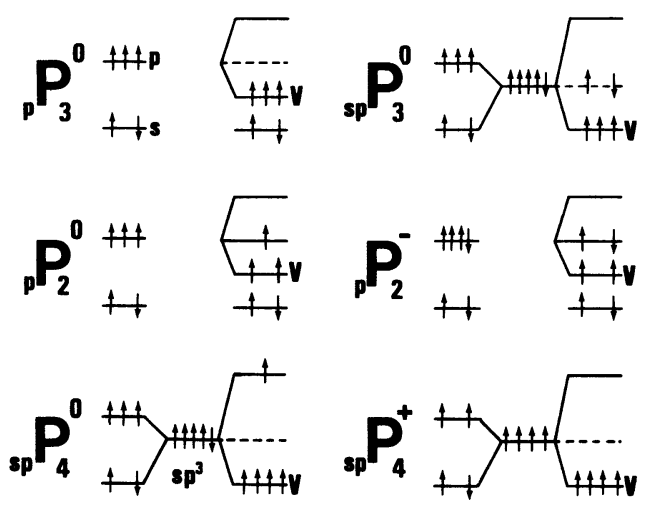

Fig. 22. - Possible defect states in amorphous arsenic after Greaves et al. [32]. Electron occupations are also shown before and after bonding. « $\mathrm{V}$ » indicates bonding electrons.

amorphous arsenic. Optical fatigue phenomena which is similar to photoquenching at the EL2 family are very common in amorphous materials. In fact, photoluminescence quenching by illumination with $1.1 \mathrm{eV}$ light, which is identical to photoquenching of the EL2 family, has been observed in amorphous arsenic [33]. Photo-induced absorption, instead of photoquenched absorption was observed near the midgap energy in amorphous arsenic [33]. These similarities lead to the idea of arsenic clusters for the origin of EL2 family.

When one makes an analogy between an amorphous arsenic and EL2 family in GaAs, it is necessary to consider the effects of periodic crystal potential on energy levels and the dynamic characteristics of amorphous arsenic. Actually, the ESR spectra for both materials show both similarity and dissimilarity, and the effects of crystal potential are obvious. This suggests that sizes of clusters should be neither too large as to isolate the effect of GaAs matrix nor too small as to eliminate the characteristics of amorphous arsenic.

A large metastable relaxation as stated in the item (iv) is very suggestive. It is inferred that various defect reactions take place when charged states are changed by illumination. In fact, three reactions have been considered in amorphous arsenic by Greaves et al. [32]

$$
\begin{gathered}
2{ }_{\mathrm{p}} \mathrm{P}_{2}^{0} \rightleftarrows{ }_{\mathrm{p}} \mathrm{P}_{2}^{-}+{ }_{\mathrm{sp}} \mathrm{P}_{4}^{+} \\
2{ }_{\mathrm{sp}} \mathrm{P}_{4}^{0} \rightleftarrows{ }_{\mathrm{p}} \mathrm{P}_{2}^{-}+{ }_{\mathrm{sp}} \mathrm{P}_{4}^{+} \\
{ }_{\mathrm{p}} \mathrm{P}_{2}^{0}+{ }_{\mathrm{sp}} \mathrm{P}_{3}^{0} \rightleftarrows{ }_{\mathrm{p}} \mathrm{P}_{3}^{0}+{ }_{\mathrm{sp}} \mathrm{P}_{4}^{0} .
\end{gathered}
$$

4.2 COMPARISON WITH OTHER MODELS FOR EL2. Microscopic models can be classified into three groups ; isolated $\mathrm{As}_{\mathrm{Ga}}$, vacancy-related complex with $\mathrm{As}_{\mathrm{Ga}}$ and excess arsenic atom-related complex involving $\mathrm{As}_{\mathrm{Ga}}$. Besides the family nature of EL2, it should be recalled that the structure is required to explain the arsenic-rich related and the metastable natures of EL2.

A shuttling motion of an arsenic atom between $V_{\mathrm{Ga}}$ and $\mathrm{As}_{\mathrm{Ga}}+V_{\mathrm{As}}$ has been shown to have a metastability from theoretical calculations [34, 35]. Since this defect has a stable state near the latter configuration, however, the expected symmetry of the stable state is $\mathrm{C}_{3 V}$ which is in contradiction to the result of stress measurement [36]. This model has another disadvantage that the defect is not a donor but an acceptor depending on the conduction type. Bar-Yam and Joannopoulos [35], therefore, assumed a divacancy, $2 V_{\mathrm{Ga}}$, which dissociates into $V_{\mathrm{As}} \mathrm{As}_{\mathrm{Ga}} V_{\mathrm{Ga}}$, Although this defect can successfully explain the p-type conversion of SI GaAs after heat treatment [37], the symmetry problem still remains unsolved. This is the reason why Baraff and Schluter [34] considered this defect to be an "actuator defect " of EL2, which should experience an aggregation with other defect(s).

$A s_{G a}+A s_{I}$ is very similar to the model proposed in the present study. Bardeleben et al. [38] performed an annealing study and attributed the regeneration of EL2 at low temperatures to mobile $\mathrm{As}_{\mathrm{I}}$. Thus, they proposed that EL2 is not an isolated antisite but $\mathrm{As}_{\mathrm{Ga}}+\mathrm{As}_{\mathrm{I}}$. They explained the metastability of EL2 by putting an As atom at the second nearest interstitial site of $\mathrm{As}_{\mathrm{Ga}}$ at the normal state, which gives rise to the ESR signal and the $T_{\mathrm{d}}$ symmetry. Assuming $\mathrm{As}_{\mathrm{I}}$ to be pulled towards $\mathrm{As}_{\mathrm{Ga}}$ in the metastable state, $\mathrm{As}_{\mathrm{Ga}}$ wavefunction is largely disturbed and no more ESR signal is likely to be observed. A total energy calculation was also carried out for this defect and an ESR-active center was found [39]. It was further predicted that photoexcitation drives the $A s_{I}$ towards $A s_{G a}$ so that the system is transformed to a metastable state. Experimentally, Spaeth [40] found a number of ODENDOR lines some of which cannot be attributed to an isolated $\mathrm{As}_{\mathrm{Ga}}$. He successfully explained these lines by assuming that $\mathrm{As}_{\mathrm{Ga}}$ exists in a complex form with $\mathrm{As}_{\mathrm{I}}$ on the tetrahedral site from the fitting of spin Hamiltonian.

It should be recalled, however, that association with only one $\mathrm{As}_{\mathrm{I}}$ can never explain the family characteristics in the stable-metastable configurations described in this study, even if a family of deep levels may be observed according to the $\mathrm{As}_{\mathrm{I}}$ movement. It seems therefore advantageous to assume a complex in which more than one $\mathrm{As}_{\mathrm{I}}$ is associated. Recently, a thermodynamical consideration was made by Wada and Inoue [41], in which the outdiffusion data of EL2 were found to be well explained by assuming a four- $\mathrm{As}_{\mathrm{I}}$ cluster. They predicted that a final form of $\left(\mathrm{As}_{\mathrm{I}}\right)_{2}\left(\mathrm{As}_{\mathrm{Ga}}\right)_{2}$, for instance, would behave like EL2 by trapping two (or more) $\mathrm{Ga}$ vacancies.

Aggregate of $\mathrm{As}_{\mathrm{Ga}}$ also belongs to the category of 
excess arsenic atom-related defects. These models are mainly based on the ESR results and in an attempt to overcome the inconsistencies between the characteristics of EL2 and $\mathrm{As}_{\mathrm{Ga}}$ signal. Meyer and Spaeth [42] performed a photoquenching experiment on $\mathrm{As}_{\mathrm{Ga}}$ signal in $\mathrm{MCD}$ with changing the excitation intensity. EL2-type quenching occurred only at a high excitation level, whereas the bleached $\mathrm{As}_{\mathrm{Ga}}$ had a different recovery characteristics from EL2. They interpreted the result in such a way that EL2-type quenching takes place when $\mathrm{As}_{\mathrm{Ga}}$ defects form an aggregate and nearby defects are simultaneously photoexcited. Thus, they proposed an $\mathrm{As}_{\mathrm{Ga}}$-aggregate model. However, the EL2 absorption was quenched at low intensities at which no $\mathrm{As}_{\mathrm{Ga}}$ quenching was observed. Aggregation (complex formation) of $\mathrm{As}_{\mathrm{Ga}}$ requires either an aggregation of $V_{\mathrm{Ga}}$ which trap $\mathrm{As}_{\mathrm{I}}$ or $\mathrm{As}_{\mathrm{I}}$-aggregate which trap many $V_{\mathrm{Ga}}$. A complete occupation of $\mathrm{Ga}$-sites by $\mathrm{As}_{\mathrm{I}}$ are hardly expected and it is more likely that $V_{\mathrm{Ga}}$ or $A s_{\mathrm{I}}$ are also involved in the excess-arsenic defect aggregate. Therefore, this type of defects can be also identified as As-clusters.

\section{Summary.}

Studies on the electrical and optical properties of EL2 in various GaAs crystals are described especially in view of the family characteristics. Together with the variation in the trap energy levels, those observed in the photoquenching effect (transitions between the normal and the metastable states) as well as the transition rate to the excited state are shown to exist. Change of EL2 centers after heavy particle bombardment and low temperature annealing indicate that the defect structure responsible for EL2 is sizable, in which mobile interstitial As atom(s) are involved. Based on the experimental results, validity of the As-cluster model for the origin of EL2 is presented and correlated with the models proposed by other investigators.

\section{Acknowledgment.}

The authors are grateful to Dr. M. Taniguchi of Nippon Mining Co. Ltd. for carrying out experiments and discussions in the early stage.

References

[1] Sakai, K. and Ikoma, T., Appl. Phys. 5 (1974) 165.

[2] Martin, G. M., Mittoneau, A. and Mircea, A., Electron. Lett. 13 (1977) 191.

[3] Henry, C. H. and LANG, D. V., Phys. Rev. B 15 (1977) 988.

[4] Chantre, A., Vincent, G. and Bois, D., Phys. Rev. B 23 (1981) 5335.

[5] Vincent, G. and Bois, D., Solid State Commun. 27 (1978) 431.

[6] Kaminska, M., Skowronski, M., Lagowski, J., Parsey, J. M. and Gatos, H. C., Appl. Phys. Lett. 43 (1983) 302.

[7] Huber, A. M., Linh, N. T., Valladon, M., Debrun, J. L., Martin, G. M., Mircea, A. and Mittoneau, A., J. Appl. Phys. 50 (1979) 4022.

[8] Wagner, R. J., Krebs, J. J., Stauss, G. H. and White, A. M., Solid State Commun. 36 (1980) 15.

[9] Holmes, D. E., Chen, R. T., Elliott, K. R. and KirkPATrick, C. G., Appl. Phys. Lett. 40 (1982) 46.

[10] Van Vechten, J. A., J. Electrochem. Soc. 122 (1975) 419 and 423.

[11] Meyer, B. K., Spaeth, J.-M. and Scheffler, M., Phys. Rev. Lett. 52 (1984) 851.

[12] Bachelet, G. B. and Scheffler, M., Proc. 17th Int. Conf. on Defects in Semiconductors, Eds L. C. Kimmerling and J. M. Parsey, Jr. (AIME, Warrendale, 1985) p. 199.

[13] Taniguchi, M. and Iкомa, T., J. Appl. Phys. 54 (1983) 6448.
[14] Taniguchi, M. and Iкoma, T., Appl. Phys. Lett. 45 (1983) 69.

[15] Watanabe, M. O., Tanaka, A., Nakanishi, T. and ZohtA, Y., Jpn J. Appl. Phys. 22 (1983) L429.

[16] Yahata, A. and Nakajima, M., Jpn J. Appl. Phys. 23 (1984) L313.

[17] TANIGUCHI, M. and IKoma, T., Semi-Insulating III$V$ Materials, Evian 1982 (Shiva, London, 1982) p. 283.

[18] Taniguchi, M. and Iкомa, T., Gallium Arsenide and Related Compounds, Inst. Phys. Conf. Ser. No. 65 (1983) p. 65.

[19] Ikoma, T., Taniguchi, M. and Mochizuki, Y., Gallium Arsenide and Related Compounds, Inst. Phys. Conf. Ser. No. 75 (1985) p. 65.

[20] Vincent, G., Bois, D. and Chantre, A., J. Appl. P.hys. 53 (1982) 3643.

[21] Martin, G. M., Appl. Phys. Lett. 39 (1981) 747.

[22] Leyral, P., Vincent, G., Nouhallat, A. and VINCENT, G., Solid State Commun. 42 (1982) 67.

[23] Levinson, M., Phys. Rev. B 28 (1983) 3660.

[24] Mochizuki, Y. and Iкомa, T., Jpn J. Appl. Phys. 24 (1985) L895.

[25] Mittoneau, A. and Mircea, A., Solid State Commun. 30 (1979) 157.

[26] Mochizuki, Y. and Iкомa, T., Semi-Insulating III$V$ Materials, Hakone 1986, Eds H. Kukimoto and S. Miyazawa (Ohm-sha, 1986) p. 323.

[27] Mochizuki, Y. and Iкомa, T., Mater. Sci. Forum 10-12, Part 1, p. 323. 
[28] Skowronski, M., LAgowski, J. and Gatos, H. C., J. Appl. Phys. 59 (1986) 2451.

[29] Okumura, T., Jpn J. Appl. Phys. 24 (1985) L437.

[30] Makimoto, T., Taniguchi, M., Ogiwara, K., IKOMA, T. and OKUMURA, T., Extended Abstracts of 16th Conf. on Solid State Devices and Materials (1984) p. 189.

[31] Lagowski, J., Gatos, H. C., Parsey, J. M. Jr., WADA, K., KaminSKa, M. and WaluKIEWICZ, W., Appl. Phys. Lett. 40 (1982) 342.

[32] Greaves, G. N., Elloitt, S. G. and Davis, D. A., Adv. Phys. 28 (1979) 49.

[33] Bishop, S. G., Storm, V. and TAYlor, P. C., Solid State Commun. 18 (1976) 573.

[34] Baraff, G. A. and Schluter, M., Phys. Rev. Lett. 55 (1985) 2340.

[35] Bar-Yam, Y. and Joannopoulos, D., Proc. 18th Int. Conf. on Physics of Semiconductors, Ed. O. Engstrom (World Scientific Publishing) 2 (1987) 809.
[36] Kaminska, M., Skowronski, M. and Kuszko, W., Phys. Rev. Lett. 55 (1985) 2204.

[37] Lagowski, J., Gatos, H. C., Kang, C. H., SkowRONSKI, M., Ko, K. Y. and Lin, D. G., Appl. Phys. Lett. 49 (1986) 892.

[38] Von Bardeleben, H. J., Stievenard, D., DereSMES, D., Huber, A. and Bourgoin, J. C., Phys. Rev. B 34 (1986) 7192.

[39] Schluter, M. and Barraf, G. A., Proc. 18th Int. Conf. on Phys. Semiconductors, Ed. O. Engstrom (World Scientific Publishing) 2 (1987) 793.

[40] Spaeth, J.-M., Semi-Insulating III-V Materials, Hakone 1986, Eds. H. Kukimoto and S. Miyazawa (Ohm-sha, 1986) p. 299.

[41] Wada, K. and Inoue, N., Appl. Phys. Lett. 47 (1985) 945.

[42] Meyer, B. K. and Spaeth, J.-M., J. Phys. C 18 (1985) L99. 